\title{
Exploring Fathering Roles in Low-Income Families: The Influence of Intergenerational Transmission
}

\author{
Jeffrey Shears, Jean Ann Summers, Kimberly Boller, \& Gina Barclay-McLaughlin
}

\begin{abstract}
This study explores the meaning of fathering among men identified as fathers or father figures of 24-month-old children enrolled in Early Head Start research sites. Fathers were asked open-ended questions about their experiences of being fathers and their relationships with their own fathers. These men spoke of how important "being there" was for them in their relationship with their child as well as how the relationship with their own fathers influenced them as a parent. This study supports the theory of intergenerational parenting and furthers our knowledge and understanding of what some men feel are important aspects of being a good father. A theoretical framework on why men may model their father's behaviors is offered, as are implications for practitioners.
\end{abstract}

n 1995, President Clinton requested that federal agencies assume greater leadership in promoting father involvement. As a result, federal agencies were asked to review their programs and policies with an eye to strengthening the role of fathers in families and highlighting fathers' contributions to their children's well-being. In addition, federal agencies were instructed to improve their data collection on fathers. Concurrently, the federal Fatherhood Initiative began to take stock of the research conducted on fathers since the 1960s. It found that there were some limitations to the available fathering data. Most of the existing work had been done on middle-class samples; used mothers as proxy for fathers; and focused on one dimension of fathers' involvement at a single point in time. The Fatherhood Initiative led to recommendations for improving data collection on the nature and outcomes of father involvement. These recommendations, found in the Nurturing Fatherhood report, were based in part in the realization that the household survey-the basic data gathering tool for demographic and behavioral science research on the family, labor force, and fertility - was based on outdated assumptions about the stability of the household (Federal Interagency Forum on Child and Family Statistics, 1998b). This methodological problem resulted in a "male undercount" problem. Researchers and policy makers were urged to expand their perspective: to attend to both marital and nonmarital relationships from the vantage points of women and men; to conduct longitudinal studies that follow the process of fertility and family formation across the life span; and to improve data gathering on the motivations, attitudes, and intentions underlying childbearing of men and women in all types of relationships. The Nurturing Fatherhood report also highlighted the need to further investigate the meaning of fatherhood and the motivations underlying fatherhood. Tanfer \& Mott (1997) had also reported that there was widespread reliance on 
fatherhood research using data collected from the mothers, on mothers' reporting of fathers' attitudes and behavior, and on mothers' reports of the quality of the relationships fathers had with their children.

Tanfer \& Mott (1997) reported that much of what is known about fathers was obtained from mothers' reports. They suggested that there is a need for new data collection efforts that focus specifically and systematically on fatherhood issues using extensive reports from fathers. In addition to collecting data from probability samples and utilizing a longitudinal design, it was also deemed important to sample non-White and non-middle-class, low-income families. They said that it is essential that such surveys include the collection of attitudinal information on a continuous basis, given the sensitivity of attitudes to life cycle events. They further suggested that small, nonprobability samples or convenience samples are also important. The results of such studies may be useful for hypothesis testing, measurement development, and exploratory work. As a result, a qualitative ethnographic study that consists of fathers from various locations nationally may enhance our understanding of the diverse meanings of fatherhood and formulation of sound conceptualization and measurement of many dimensions of fatherhood. Cherlin and Griffith (1998) suggest that there are several concerns regarding the quality and utility of information obtained from mothers about the role of fathers in children's lives.

Many studies currently ask both mothers and fathers the same questions on parenting surveys because researchers are not yet certain what to ask fathers and because studies have not yet pointed to any distinctive understanding of fathers' roles. Given the research issues in some of the previously mentioned fathering research, there is a need to continue to examine various fathers' experiences. This article adds to existing literature by exploring fathers' responses to open-ended questions in a national Early Head Start study regarding their fathering experiences and experiences with their own fathers. This exploratory study is intended to contribute to developing hypotheses about how men in low-income families from various regions in the United States see their roles as fathers and how their roles are shaped by their experiences as sons and with others in their social context.

\section{Literature Review}

Studies reveal that society is expanding the ways fathers are perceived, the duties they perform, and is broadening the definition of fathers. Marsiglio, Day, and Lamb (2000) suggest that we must revise our perceptions of the many varied forms of fatherhood. For example, unlike some earlier studies on fathering, many current studies are including nontraditional fathers, such as stepfathers, nonresidential fathers, and father 'figures' to better understand male influences on early child development (Bumpass, Raley, \&
Sweet, 1995; Hernandez \& Brandon, 2002; Shears \& Robinson, 2005). Another focus is to include fathers of low-income families and record their experiences in rearing young children. Brooks-Gunn and McLanahan (2002) report that these men are more likely to have lower levels of education, less stable employment, and more substance abuse issues. Families in this situation have been referred to as fragile families because of the unstable family relationships. Furthermore, in some studies fathers are being asked about their experiences with their own father in an attempt to better understand how intergenerational relationships influence fathers' relationships with their own children (Cowan \& Cowan, 1987, 1992; Furstenberg \& Weiss 2000; Hirschlein, Wyatt, \& Plunkett, 2001; Sagi, 1982; Thornberry, Freeman-Gallant, Shears, Robinson, \& Emde, 2002; Lizotte, Krohn, \& Smith, 2003). Cowan, Cowan, and Pearson (1996) found that fathers who had positive relationships with their own parents were more positively involved and attached to their child than were fathers who reported poor parental relationships.

\section{Fathers' Contributions}

Recent studies have begun to recognize the emotional (Lamb, 2002), psychological (Lamb, 2002; Palkovitz, 2002), and economic contributions (England \& Folbre, 2002; Graham \& Beller, 2002) that fathers make to their children's development (Federal Interagency Forum on Child and Family Statistics, 1998b). This recognition is further supported by policy makers' increased attention to fathers and father issues. For example, legislators have supported provisions in welfare reform that increase efforts in child support enforcement and have emphasized federal policy on maintaining family integrity. These reforms have encouraged states to develop fatherhood initiatives, father support programs, and other advocacy programs that focus on increasing fathers' access to their children (Curran \& Abrams, 2000).

In addition, much of the present father literature focuses on understanding the father-infant relationship (Lamb, 2002), differences between fathering and mothering, the roles that fathers play in families, and how men learn to father (Lamb, 1997; Parke \& Swain, 1976).

There has been a significant amount of research on the father-infant relationship. Studies show that fathers are emotionally connected to their infants (Bader, 1995), behave appropriately when introduced to their newborn (Rödholm \& Larson, 1982), and have hormonal changes around the birth (Storey, Walsh, Quinton, \& WynneEdwards, 2000). Research on the differences between mothering and fathering often examines the variation in the types of activities of parents. Lamb (1997) suggests that fathers, just as mothers, are attentive, sensitive, and skillful in interactions with their infants. For example, fathers alter speech patterns and are as equally responsive as mothers to infant cues (Dalton-Hummel, 1982; 
Kokkinaki \& Kugiumutzakis, 2000; Parke \& Swain, 1976). However, it has been suggested that fathers offer something unique to early infant development. Redina and Dickerscied (1976) found that fathers were more likely to be involved in social activities, play, and physical interactions. They suggest that this role as social playmate increases over time and by the child's third year fathers average more playtime with their children than mothers do. Given the types of interactions and activities fathers participate in, it should be no surprise that they may interact differently with their children than mothers do. Lamb and Lamb (1976) suggest that fathers are more likely to engage in vigorous, physically stimulating play or unusual and unpredictable play, unlike mothers who usually play games of cognitive stimulation like 'patty-cake'. Other studies report that fathers are more playful and less restrictive than mothers (Lamb, 1997; Yogman, 1981) and praise their infants more during physical play (Clarke-Stewart, 1978). Recently, Black, Dubowitz, and Starr (1999) found a modest effect of African American fathers in influencing the home environment and contributing
Encouraging and educating men

about the importance of their contri-

butions to their children may affect

their offspring for generations. ported by social learning theory. One may hypothesize that a large influence on how men interact with their children is learned from their fathers. This hypothesis is supported by Shears, Robinson, and Emde (2001) who found that relationships with their own fathers during childhood are associated with how men feel about themselves currently as fathers as well as their current attachment to their own children.

Pleck (1997) suggests two main hypotheses about the influence of how a man was fathered on his own fathering behavior and attitudes. He advises that-depending on the level of involvement of their father-men compensate for their fathers' lack of involvement or they model their own fathers' involvement. As a result, present paternal roles and attitudes in men may be strongly influenced by one's relationship and positive or negative experiences with one's father (Bauruch \& Barnett, 1986; Cowan \& Cowan, 1987, 1992; Russell, 1986; Sagi, 1982). Further studies suggest that men who had nurturing fathers will imitate those behaviors (Reuter \& Biller, 1973) and warm relationships with one's father influences to the development of cognitive skills, language skills, and behavior of their 3-year-old children.

Father roles. Father research has also examined how men perceive their roles as fathers in their families. Much of this literature reveals that many fathers value some of the more traditional roles but are embracing more modern roles such as caregiving and caretaking. Parke (1995) suggests that this increase in caregiving among fathers is a result of more mothers entering the workforce. Bozett and Hanson (1991) found an increase in caregiving and household chore activities among fathers. Other research findings indicate that there may also be differences in some caregiving activities across races and ethnicities. Housaain, Fields, Pickens, Malphurs, and Del Valle (1997) found that African American fathers spent more time in the caregiving role and were more likely to engage in the physical care, feeding, and soothing of their infants than Anglo fathers.

Intergenerational transmission of parenting. One possible contribution to father involvement is intergenerational transmission of fathering skills, defined as learning fathering from the family of origin (Cowan \& Cowan, 1987; Snarey, 1993). A study of middle-income men in Israel found that men's involvement with their children and their self-reported satisfaction as a parent was significantly associated with their present and past experiences with their fathers (Sagi, 1982). Men learning fathering activities and modeling their fathers' behaviors is sup- men to recreate a similar environment with their own child (Coysh, 1984). It is also significant to note that men may have what Daly (1993) refers to as fragmented models. Especially when men have had negative experiences with their fathers, they may choose to model positive fathering behaviors from a variety of sources, including peers and male characters portrayed in the media (Cowan \& Cowan, 1987; Parke, 1995; Sagi, 1982). It may be that these men remember negative experiences or the absent father from their childhood and make a concerted effort to not create a similar situation for their children.

Given the volume of new literature regarding fathering roles and activities, Palkovitz (2002) suggests that we are still far from understanding the contributions fathers make to their children. There is still very little research regarding how individual fathers have evolved into acquiring a more contemporary view of fathering. In short, who is the fathering model for contemporary fathers? Do fathers pattern themselves after their own fathers or some father figure? And most importantly, what do fathers bring to child rearing from their own father-son experiences? Further, most studies of fathers and their experiences were historically of middle-class, Anglo families (Lamb, 2002; Jarret, Roy, \& Burton, 2002; Toth \& Xu, 1999). The need for balance in subjects suggests that more research be directed at hearing the voices of minority and low-income fathers. 
This paper uses qualitative data from the national Early Head Start Research and Evaluation Project to explore men's experiences in being fathers in low-income families as well as how a father's relationship with his own father might affect his relationship with his child.

\section{Method}

\section{Early Head Start Research and Evaluation Project}

Early Head Start is a comprehensive, two-generation program that includes intensive services that begin before the child is born. The program concentrates on enhancing the child's development and supporting the family during the critical first 3 years of life. A national evaluation of program implementation and impact was conducted at 17 research sites by a consortium of researchers and federal funding agencies working in partnership with the Early Head Start programs. This study employed an experimental research design with random assignment of 3,001 families recruited when the children were 12 months of age or younger or during the mother's pregnancy. Mothers completed a baseline enrollment interview followed by parent services interviews at 6 , 15 , and 26 months following random assignment and at program exit. Children

\section{Fathers expressed the desire to}

move away from more traditional roles

with their children and one desire they

indicated was to hug, kiss and be

affectionate with their children. quantitative interview. Thus, the overall design of this mixed-methods research could be characterized as predominantly quantitative with an embedded qualitative component conducted parallel to the quantitative study (Creswell, Clark, Gutman, \& Hanson, 2003). Data for this article were taken from the interviews of men who were reported to be the father or father figure of the Early Head Start child at 24 months.

\section{Participants}

This study includes 16 qualitative interviews completed with fathers around the time of their child's 24-month birthday. Mothers who were enrolled in Early Head Start Research, either as comparison or program families, initially identified the participants in this study as the father/father figure of their child when the child was 2 years of age. Because of the requirements of enrollment in Early Head Start, the families and children are low-income. The men who responded about income, with the exception of 1 father, may be considered as low-income, with 3 fathers reporting income below the poverty guidelines of that year. The mean monthly income reported was $\$ 932$ with a standard deviation of $\$ 846$ and a range between $\$ 0$ and $\$ 2,800$. The men were were assessed, primary caregivers were interviewed, and parent-child interactions were videotaped when children were 14, 24, and 36 months of age. The 17 Early Head Start programs participating in the national evaluation and local research represented a wide diversity of locations, populations, culture, ethnicity, and urban or rural settings. They were located in Arkansas, California, Colorado (2 sites), Iowa, Kansas, Michigan, New York City, Missouri, Pennsylvania, South Carolina, Tennessee, Utah, Virginia, Washington (2 sites), and Vermont.

The Early Head Start national evaluation data collection focused on the primary caregiver (the mother in over 95 percent of the families) as the source of information. Data related to those fathers agreeing to participate were collected at the child's age of 24 months at 12 sites. The father study included measures parallel to the study of mothers- that is, measures of family resources and supports, knowledge of child development, parent characteristics such as education and depression, and videotaped interactions of father and child. In addition, the father study contained an embedded qualitative study involving audiotaped, open-ended questions interspersed throughout the
Latino (2) and European American (14). Their mean age was 32.6 years with a standard deviation of 10.14 years. Sixty-nine percent of the fathers reported that they completed 12 th grade and $25 \%$ of the fathers reported graduating from college. The men also reported on their residential status: $69 \%$ (11) of the fathers reported being residential and biological fathers, $13 \%$ (2) reported being nonresidential biological fathers, and 19\% (3) reported being residential nonbiological fathers. The focus children of the fathers in this study were $44 \%$ (7) female and 56\% male (9). Six men reported having one to five children in addition to the focus child. Fathers also reported on the time spent with the focus child. To give an indication of how often the father and child interacted, men were asked, "In the past month how often have you spent 1 or more hours a day with the child." Ninety-four percent (15) responded that they spent at least 1 or more hours a day with their child every day or nearly every day.

Data from this report were obtained through a purposive sampling process (Anfara, Brown, \& Mangione, 2002) of 16 of the transcripts drawn from a larger pool of transcripts. Purposive sampling involves selection of respondents who 
may represent a variety of responses and/or who may represent "key informants," that is, those with a broader or more articulate perspective (Lincoln \& Guba, 1985). In this process, we selected at least 1 transcript from each of the sites participating in the father study, rejecting those transcripts that contained incomplete or minimal responses. Such samples are considered appropriate when the purpose of the study is exploratory and intended to identify a range of issues and the relationships among them, rather than to identify the prevalence of different factors (McAllister \& Summers, 2000).

\section{The Interview Protocol and Procedure}

The purpose of the embedded qualitative study was to gain more open-ended, exploratory information about fathers. The rationale for a qualitative component in the Early Head Start study was that so little information was available about fathers-especially from low-income backgrounds-that some basic, exploratory data were needed to develop a sense of how fathers perceive and interpret the issues of parenting and program supports. Standards of rigor for qualitative studies that are analogous to quantitative studies include the use of techniques to enhance credibility (analogous to validity), transferability (analogous to generalizability), and dependability (analogous to reliability) of the research process (Anfara et al., 2002). The qualitative interview protocol included six primary or "grand tour" (Miles \& Huberman, 1994) items:

- What does being a "good father" mean to you?

- How has becoming a father impacted your life?

- Talk about your experiences with your own father.

- What kinds of help or support do you get to do your job as a father?

- What gets in the way of being a father?

- What are you proudest of about your child?

For each of these questions a series of suggested probes was developed for use by interviewers. The probes were intended to elicit more elaborate responses to these questions. All interviewers received training on the techniques of qualitative interviewing and participated in two projectwide conference calls to discuss and revise the probes throughout the data collection phase. This process is a type of peer debriefing intended to enhance the credibility of the study; an audit trail of the changes in protocols was also kept to document the dependability of the study (Anfara et al., 2002).

This study reports results of responses to the first and third of the listed questions for these 16 fathers. Copies of the selected transcripts were distributed to each member of the qualitative research team for this study. Each team member independently read and analyzed the 16 transcripts sequentially. In other words, he or she identi- fied themes emerging from the two questions that were the focus of this study (father roles and experiences with own father) for the first transcript. In subsequent transcripts, the same or new themes were highlighted. This process is called the constant comparison method of data analysis and is used to provide potential evidence for transferability (Anfara et al., 2002). Following these first readings, the team discussed the emergent themes and issues with respect to the questions of father-perceived roles and fathers' experiences. Next, we systematically pulled the relevant comments from each transcript and attempted to sort those comments into a framework based on our preliminary discussions. Finally, we reviewed the results of that procedure, reached consensus about a modified framework, and developed the conclusions presented here. This process is a type of peer triangulation utilized in qualitative research to develop greater credibility (Patton, 2001).

\section{Results}

Given the size of this sample, the following analysis should be considered exploratory and the findings provisional. The intent of this study was not to test theory but rather to build theory from the ground up for future research on fatherhood and to give voice to men. In a number of ways this group of fathers maybe similar to other fathers presented in the growing body of research on this topic, but the ways they talk about their decision to parent may distinguish these men from the profile of those described in historical studies and raise additional issues for further research.

The first of two questions for this study is "What does being a good father mean to you?" Fathers responded with a host of roles and activities they did with their children. These fell into three broad categories: (a) a broad, allencompassing concept they called being there, which included both physical and emotional presence for their children; (b) engaging in a range of teaching, providing, and protection roles that we identified as traditional father roles; and (c) engaging in more contemporary coparenting roles with their child's mother, which we labeled contemporary father roles. Traditional versus contemporary father roles have been identified by father researchers (Pleck \& Pleck, 1997) who have described father roles as changing in response to societal trends, such as more women entering the workforce. More traditional roles prescribe a stricter role division between mothers and fathers, and ascribe to fathers such roles as providers, teachers, playmates, protectors, and a force for security (i.e., being there). More contemporary views of parenting, on the other hand, view both parents as sharing roles or coparenting. Thus, fathers with more contemporary perceptions of their roles describe their role as a parent in partnership with the mother and emphasize engaging in 
caregiving chores and giving affection and emotional support to their children (Booth \& Amato, 1994).

In the second research question for this study, fathers were asked to discuss their perceptions of experiences with their own fathers. Specifically, fathers were asked to "Describe the relationship with your dad while you were growing up." They reported that their experiences with their own fathers were variously positive, negative, or mixed. In some cases, men reported that their own biological father was not in the picture, but that they learned about being a father from their stepfather or from another important man in their life. Thus, some respondents had positive experiences with one father figure and negative experiences with another. Most of the men responded that there were things they wished their father had done differently, and they were actively working not to repeat similar behaviors with their children.

Following the qualitative procedure involved in generating grounded theory (Strauss \& Corbin, 1998), we reexamined the transcripts to determine whether there were relationships between men's experiences with their own fathers and the development of their views of their roles as a father. In the following sections, we describe these respondents' perceptions and their experiences with their own fathers with respect to (a) being there, (b) engaging in traditional roles, and (c) engaging in contemporary father roles.

\section{Being There}

Fathers were asked, "What does being a good father mean to you?" and they consistently voiced being there for their child as part of their response. The concept of "being there" carried various dimensions, including being there physically and emotionally for their children. The "being there" theme was also reflected in responses to our question asking fathers to reflect on their experiences with their own father. Many, in describing their father, said he either "was there" or he "was not there" for them. Being there had different meanings for fathers, but it generally consisted of more than a physical presence. Men's memory of their own father suggested they fell into three categories of the being there theme: (a) the absent father, (b) the always there father, and (c) fathers who were there in some instances or some dimensions.

In reflecting on the negative experiences with his father, one father said,

It means being there, playing, doing things together, showing him the way to be, just by the way I interact with his mother and with everyone else.... When I was his age I never had anyone; my dad was never home.... I don't want to see him [child] end up looking for a father figure for the first 5 years of his life. Still when I look back on it, he wasn't there.
Another father shared thoughts about his negative experiences with his father when he said,

It was very authoritative.... As I was younger, my dad was constantly building his business, and so it was like I never got to see him a lot. And so it was like when he came home it was just like a whirlwind and he wanted everything done that way and he wanted it done. And if it wasn't done right, there was a spanking involved.... As a teenager one of the things I despised, was the way that my dad treated me. And the way that I communicate and handle my own kids is a lot different than my dad. I just don't rage at them. And if they don't do things exactly right, I won't beat the hell out of them.

Respondents who reported that they had an absent father generally expressed regret that their fathers had been unavailable, which usually resulted in them wanting to really be there for their own children. These men seemed to want to compensate for areas that were missing in their childhood experiences with their own fathers. Some fathers also reported having mixed experiences with their own fathers. One young father revealed the following:

I think my father thought of himself as mainly the provider. He wasn't really a warm person. But we all had the feeling that he loved us, he just wasn't very demonstrative about it... I think he would view himself in his main role in the family as the provider. And I would not like that to be my only role in the family.

Although these men were attempting to use the positive aspects of their relationships with their fathers to raise their own children, they recognized the void in their own upbringing and reported that they were attempting to be more available to their children. In many cases, men excused their fathers for not being there with an understanding that fathering roles are different now. As a result, many men expressed that their father may have been there, but they wanted to extend the fathering role further with their own children. Lastly, many men reflected on the positive relationship they had with their father. As one dad said,

Aww, he was a good dad! He worked in the city, so we didn't see him all day. But he came home at night, and he was always playing ball with me ... he was always there for us, we helped him work on the car.

These men expressed how important it was for their fathers to be emotionally and physically available for them. The meaning of being there is important, and usually expressed either wanting to be there or having a father who was there for them. 


\section{Traditional Father Roles}

Fathers identified being there as involving several traditional roles including provider, protector, role model, disciplinarian, entertainer/socializer, and teacher. These roles provide insight about men's experience with their fathers as well as indications about how the fathers wish to be there for their children. Many fathers mentioned that being a good father means being a provider and being financially responsible for their children.

Fathers also talked about being a protector as a form of being there and many fathers wanted to be there for the children to keep them from harm and danger. The phrases fathers commonly used as examples of being a protector included "watching out for them" or "looking after them." One dad explained his son's behavior:

\begin{abstract}
We go to the mountains or something like that and we're standing in the dark in the forest, and he'll sit there and kind of, he'll start to lean over towards me and that kind of stuff. He just keeps calling my name, you know, even though I was right there. Daddy? Daddy?
\end{abstract}

In addition, a number of fathers also felt that it was important to set a good example for their children. The phrase "set a good example" was heard throughout the interviews and was perceived as being an important role for these dads. One dad described setting an example this way:

How you have to watch what you say and do around them. You've got to set a good example for them too. Just show them what's right and what's wrong and all that. I didn't realize how all that went-trying to show them to the bathroom and all that stuff.

These men also voiced how important it was to be the authority figure and make sure rules and regulations were followed. In some instances, fathers indicated their father was too strict in his discipline and wished he had not been. However, in most cases, fathers appreciated the discipline of their father, particularly if he was there for them in other ways.

Father as teacher was also a role we heard about from the men and this took many forms, from teaching values to academic skills to sports and other recreational activities. Fathers want to teach their children values. In general, fathers saw the teaching role as a significant one. One dad said fathers should

Teach right values - try to teach kids not to steal, not to lie, it's not right to walk up and hit somebody, call them names. Don't pick on them because they're Black, White, whatever... Respect is another thing to teach them. Respect everybody as you would want to be respected.
Another example of teaching that was prevalent in the interviews was of fathers who learned how to fish, hunt, or play ball from their fathers. Fathers cherished time spent with their own fathers, especially when their father was in a teaching role. Many fathers planned to teach their children some of the same activities their fathers had taught them.

\section{Contemporary Father Roles}

Fathers reflected on experiences with their fathers and expressed the desire to be available to their children in expanded ways. Although many of these fathers felt it important to be provider, teacher, role model, and the other more traditional roles presented earlier, they also felt strongly about some other fathering roles that we have categorized as more contemporary. The three contemporary roles include father as caregiver, as partner with the child's mother, and as a source of affection and emotional support.

We categorized the caregiver role as contemporary despite the fact that historically a small proportion of families have been headed by single fathers and single fathers have provided primary caregiving. The contemporary view on the caregiver role is that we are now hearing fathers say that they see nurturance and relationship as part of what it means to be a father and that they enjoy this aspect of being a parent. Many fathers in this study desired and participated in the hands-on experience of parenthood-feeding, diapering, and so forth. Some fathers expressed hesitation early in their children's lives about participating in many of these activities, but most thought it was an important part of being a good father. As one dad said,

I've been a hands-on dad ever since she was born. I've always done more than my share, I think.... You've got to keep an eye on them at all times, you can't relax too much.... You've got to be changing the diaper, keeping after her and making sure she's not eating dirt.

The saying that "the most important thing a man can do for his children is love their mother" is a great example of what fathers perceived as important. Many fathers expressed being there as staying with their children's mother. In addition, some fathers wished their fathers had stayed with their mothers. These men seemed to feel that children living in a two-parent environment were better off. They believed this environment provided more structure and stability for child rearing.

Playing and entertaining children were seen as another type of hands-on interaction that many fathers wanted to participate in. Several fathers seemed to like the makebelieve and play time more than their children! These fathers really looked forward to playing and entertaining their children. One father responded,

Like me and my brother, we always take the kids out like at least more than twice a week-we take them 
somewhere like McDonalds and I play with them... Like, we are always having fun without the mothers around or just us and the kids.

Fathers generally expressed that it's worth being a father when their children show them affection, like giving them a hug or saying "I love you." They tended to savor those moments of affection with their children and valued giving the children affection and always letting their children know how much they love them. We heard this most often when fathers expressed disappointment that their dads were not affectionate. Fathers expressed the desire to move away from more traditional roles with their children and one desire they indicated was to hug, kiss and be affectionate with their children. In addition, some men were able to reflect on how their fathers were good dads, but were not affectionate. It should be noted that some men had an overall positive reflection of their fathers, but identified the lack of affection as something they wish to overcome with their own children.

When asked what some of the rewards of being a father are, one dad said, "This right here, when they snuggle up with you. Not every child will come up to you like that. And then my son, he's even worse. He's hanging on me all the time. He's always sticking with me."

\section{Discussion}

The results of this study show that Early Head Start fathers feel it is important to be involved for their children. These results are similar to those of Allen and Doherty (1996), who found an identical theme in their study of African American adolescent fathers and African American financially established fathers. The men in the current study also reported that being there for their child was an important aspect of being a good father. These Early Head Start fathers defined good fathering as filling more traditional roles (Brayfield, 1995), but also included more contemporary roles such as caregiver, partner with mother, and being affectionate. This supports other studies (Wilkie, 1993) that suggest there is a shift in how men perceive their roles and that there may be an overlap in areas of parenting that have historically been viewed as a role for the mother.

Additionally, fathers expressed how their presence-or in some cases, absence-affected the way they interacted with their children. This was especially evident when fathers discussed participating in many of the same activities (playing ball, camping, and fishing) they experienced with their dads. This clearly shows an association between a father's experiences with his father and activities he participates in or plans to do with his child.

It should be noted that there was little variation in fathers' responses based on demographic information such as reported residential status, relationship status, reported amount of time spent with the focus child, the gender of the focus child, or the numbers of reported biological children in addition to the focus child. In addition, responses of the Hispanic fathers were very similar to those of Anglo fathers. This suggests the possibility of a unifying theme in highly involved fathers of lowincome families.

These results support similar findings of other studies (Brayfield, 1995) that suggest fathering in low-income families is not very different from that in other socioeconomic classes. Further studies on this topic should examine differences across racial and ethnic populations of low-income families. In addition, empirical studies may attempt to understand how mothers influence the type and frequency of fathers' involvement with their children. Finally, studies need to explore how much fathers contribute to mothers' involvement with children. That is, are mothers the only parent who influence the other parent's roles, or do fathers also influence mothering.

\section{Limitations}

One of the limitations, given the research design, use of open-ended questions, and the preliminary focus of this study, is that the findings cannot be generalized to all fathers or to the larger population of fathers participating in the Early Head Start research study. In addition, these are preliminary data; it is expected that over 800 men will be interviewed before the research project is complete. Although we recognize the need to include a diverse ethnic and racial sample of fathers, that was not this study's focus, and as a result, this study does not offer a diverse participant sample. As an embedded qualitative study, a further limitation was the lack of freedom given to interviewers to pursue themes and to probe emerging issues. Because different people acted as analysts and interviewers, there was a lag in time between changes in the probes. Further, some of the interviewers were primarily trained as quantitative methodologists, and thus there was a great deal of variance in the skills of the interviewers. In other words, in some ways the integrity of the qualitative study was constrained by its placement within a larger quantitative paradigm (Newman, Ridenour, Newman, \& DeMarco, 2003).

\section{Implications for Practice}

This study helps us to understand more about fathering of young infants. It examines the traditional and contemporary roles of fathering and sheds some light on intergenerational transmission or how prior experiences with one's own father influences fathering practices with one's child. Participants were able to express and reflect on their experiences in ways that we often do not associate with men. They generally found value in the more traditional fathering roles and expressed how they were 
appreciative of fathers who valued these more traditional roles. However, these men also verbalized their desire to not only participate in the more traditional roles, but also expand their roles to include more contemporary activities. These fathers discussed how they fed, bathed, and were affectionate with their children, and how these experiences were not only sometimes necessary, but also valuable to them.

This study reminds us that the activities and attitudes of fathers are changing. As the family structure continues to change as a function of more women moving into the work force and of increases in divorce rates, what we know about fathers will continued to be challenged. Although there has been an increase in fathering research studies and available literature, researchers must be cognizant that the process and topic under study is constantly changing. In addition, we need to be mindful that men from various economic levels might offer different views of their fathering roles, and we need to remain diligent to also hear their varied voices.

In addition, there are specific implications for practice given that many of the families we work with may be considered fragile families by virtue of their limited resources and/or unstable relationships. Further emphasis on the unique contributions fathers offer in early infant development is warranted. One area that may need to be continually addressed in practice situations is education. Families need to know and understand the importance of fathers to children's emotional and financial well-being. The focus on education and information may be expanded to include father groups for fragile families. In many cases, young men may not understand their own importance, and a solution may simply be providing information that says that being there for your child has specific benefits.

Another way that practitioners may influence families is to continue to support fathers' access to all aspects of children's lives. This may present a measure of difficulty, especially with infants and toddlers, as many mothers may be protective of their turf. One role of mothers of young children is that of gatekeeper and a mother may be unwilling to share their parental roles with the father. However, this article supports the trend that many fathers are interacting with their children in a much more contemporary way. Families should understand that this trend is appropriate and that young children benefit from many of the contemporary activities of fathers.

Simply understanding the importance of the fathering role may keep many men involved in their children's lives. Men who have positive emotional relationships with their fathers have more positive relationships with their own children. Encouraging and educating men about the importance of their contributions to their children may affect their offspring for generations.

\section{References}

Allen, W. D., \& Doherty, W. J. (1996). The responsibilities of fatherhood as perceived by African-American teenage fathers. Families in Society, 77, 142-155.

Amato, P. R. (2000). The consequences of divorce for adults and children. Journal of Marriage and the Family, 62, 1269-1287.

Anfara, V. A., Jr., Brown, K. M., \& Mangione, T. L. (2002, October). Qualitative analysis on stage: Making the research process more public. Educational Researcher, 28-38.

Bader, A. P. (1995). Engrossment revisited: Fathers are still falling in love with their newborn babies. In J. L. Shapiro, M. J. Diamond, \& M. Greenberg (Eds.), Becoming a father (pp. 224-233). New York: Springer.

Baruch, G. K., \& Barnett, R. C. (1986). Fathers' participation in family work and children's sex-roles attitudes. Child Development, 57, 1210-1223.

Black, M. M., Dubowitz, H., \& Starr, R. H. (1999). African American fathers in low-income, urban families: Development, behavior, and home environment of their three-year-old children. Child Development, 70, 967-978.

Brayfield, A. (1995). Juggling jobs and kids: The impact of employment schedules on fathers caring for children. Journal of Marriage and the Family, 57, 321-332.

Brooks-Gunn, J. \& McLanahan, S. (2002). Father involvement: Social policy and intervention. In C.S. Tamis-LeMonda \& N. Cabrerea. (Eds.). Handbook on father involvement (pp. 455-459). Mahwah, NJ: Erlbaum.

Booth, A., \& Amato, P. R., (1994). Parental gender role nontraditionalism and offspring outcomes. Journal of Marriage and the Family, 56, 865-877.

Bumpass, L. L., Raley, R. K., \& Sweet, J. A. (1995). The changing character of stepfamilies: Implications of cohabitation and nonmarital childbearing. Demography, 32, 425-436.

Bozett, F. W., \& Hanson, S. M. H. (1991). Fatherhood and families in cultural context. New York: Springer.

Cherlin, A., \& Griffith, J. (1998). Methodological issues in improving data on fathers: Report of the Working Group on the Methodology of Studying Fathers. Battelle Memorial Institute, prepared for the NICHD workshop Improving Data on Male Fertility, Family Formation and Fatherhood, Urban Institute (January, 1997), Washington, DC.

Clarke-Stewart, K. A. (1978). And daddy makes three: The father's impact on mother and young child. Child Development, 49, 466-478.

Cowan, C. P., \& Cowan, P. A. (1992). When partners become parents. New York: Basic Books.

Cowan, C. P., \& Cowan, P. A. (1987). Men's involvement in parenthood: Identifying the antecedents and understanding the barriers. In P. W. Berman \& F. A. Pedersen (Eds.), Men's transitions to parenthood (pp. 145-171). Hillsdale, NJ: Erlbaum.

Cowan, P. A., Cowan, C. P., \& Pearson, J. L. (1996). Parents' attachment histories and children's externalizing and internalizing behaviors: Exploring family systems models of linkage. Journal of Consulting and Clinical Psychology, 64, 53-63.

Coysh, W. S. (1984). Men's role in caring for their children: Predictive and concurrent correlates of father involvement. Dissertation Abstracts International, 45, 6B1909.

Creswell, J. W., Clark, V. L., Gutmann, M. L., \& Hanson, W. E. (2003). Advanced mixed methods research designs. In A. Tashakkori \& C. Teddlie (Eds.), Handbook of mixed methods in social and behavioral research (pp. 209-240). Thousand Oaks, CA: Sage.

Curran L., \& Abrams L. S. (2000). Making men into dads: Fatherhood, the state, and welfare reform, Gender \& Society, 14, 662-678.

Dalton-Hummel, D. (1982). Syntactic and conversational characteristics of fathers' speech. Journal of Psycholinguistic Research, 11, 465-483.

Daly, K. (1993). Reshaping fatherhood: Finding the models. Journal of Family Issues, 14, 510-530.

England, P., \& Folbre, N. (2002). Involving dads: Parental bargaining and family well-being. In C. S. Tamis-LeMonda \& N. Cabrera (Eds.), Handbook of father involvement (pp. 387-408). Mahwah, NJ: Erlbaum. 
Federal Interagency Forum on Child and Family Statistics. (1998a). America's children: Key national indicators of well-being. Washington, DC: U.S. Government Printing Office.

Federal Interagency Forum on Child and Family Statistics. (1998b). Nurturing fatherhood: Improving data and research on male fertility, family formation, and fatherhood. Washington, DC: U.S. Government Printing Office.

Furstenberg, F. F., \& Weiss, C. C. (2000). Intergenerational transmission of fathering roles in at risk families. Marriage \& Family Review, 29, 181-201.

Graham, J. W., \& Beller, A. H. (2002). Nonresident fathers and their children: Child support and visitiation from an economic perspective. In C. S. Tamis-LeMonda \& N. Cabrera (Eds.), Handbook of father involvement (pp. 431-454). Mahwah, NJ: Erlbaum.

Housaain, Z., Fields, T. M., Pickens, J., Malphurs, J., \& Del Valle, C. (1997). Father's caregiving in low-income African-American and Hispanic American families. Early Development and Parenting, 6, 73-82.

Hernandez, D. J., \& Brandon, P. D. (2002). Who are fathers of today? In C. S. Tamis-LeMonda \& N. Cabrera (Eds.), Handbook of father involvement (pp. 33-62. Mahwah, NJ: Erlbaum.

Hirschlein, B., Wyatt, V., \& Plunkett, S. (2001, November). The intergenerational transmission of corporal punishment and obedience parenting attitudes as mediated by parents' observable punitiveness and open communication parenting behaviors. Poster presented at the 63rd Annual Conference of the National Council on Family Relations, Rochester, NY.

Jarrett, R. L., Roy, K. M., \& Burton, L. M. (2002). Fathers in the "Hood": Insights from qualitative research on low-income African-American men. In C. S. Tamis-LeMonda \& N. Cabrera (Eds.), Handbook of father involvement (pp. 211-248). Mahwah, NJ: Erlbaum.

Kokkinaki, T., \& Kugiumutzakis, G. (2000). Basic aspects of vocal imitation in infant-parent interaction during the first 6 months. Journal of reproductive and infant psychology, 18, 173-187.

Lamb, M. E. (1997). The role of the father in child development (3rd ed.). New York: Wiley.

Lamb, M.E. (2002). Infant-father attachments and their impact on child development. In C. S. Tamis-LeMonda \& N. Cabrera (Eds.), Handbook of father involvement (pp. 93-118). Mahwah, NJ: Erlbaum.

Lamb, M. E., \& Lamb, J. E.(1976). The nature and importance of the father infant relationship. Family Coordinator, 25, 379-386.

Lincoln, Y. S., \& Guba, E. G. (1985). Naturalistic inquiry. Newbury Park, CA: Sage.

Marsiglio, W., Day, R., \& Lamb, M. E. (2000). Exploring fatherhood diversity: Implications for conceptualizing father involvement. Marriage and Family Review, 29, 269-293.

McAllister, C., \& Summers, J. A. (2000, July). Applications of qualitative methodologies to studies of Early Head Start. Washington, DC: Presented to the National Head Start Research Conference.

Miles, M. B., \& Huberman, A. M. (1994). Qualitative data analysis. Thousand Oaks, CA: Sage.

Newman, I., Ridenour, C. S., Newman, C., \& DeMarco, G. M. P. (2003). A typology of research purposes and its relationship to mixed methods. In A. Tashakkori \& C. Teddlie (Eds.), Handbook of mixed methods in social and behavioral research (pp. 167-188). Thousand Oaks, CA: Sage.

Parke, R. D. (1995). Father and families. In M. Bornstein (Ed.), Handbook of parenting: Vol. 3. Status and social conditions of parenting (pp. 27-64). Mahwah, NJ: Erlbaum.

Parke, R. D. \& Swain, D. (1976). The father's role in infancy: A reevaluation. Family Coordinator, 25, 365-371.

Palkovitz, R. (2002). Involved fathering and child development: Advancing our understanding of good fathering. In C. S. TamisLeMonda \& N. Cabrera (Eds.), Handbook of father involvement (pp. 119-140). Mahwah, NJ: Erlbaum.

Patton, M. Q. (2001). Qualitative evaluation and research methods (3rd ed.). Newbury Park, CA: Sage.

Pleck, J. H. (1997). Paternal involvement: Levels, sources, and consequences. In M. E. Lamb (Ed.), The role of the father in child development (3rd ed., pp.66-103). New York: Wiley.
Pleck, E. H., \& Pleck, J. H. (1997). Fatherhood ideals in the United States: Historical Dimensions. In M. E. Lamb (Ed.), The role of the father in child development, (3rd ed., pp.33-48). New York: Wiley.

Redina, I., \& Dickerscied, J. D. (1976). Father involvement with first-born infants. Family Coordinator, 25, 373-379.

Reuter, M. W., \& Biller, H. B. (1973). Perceived paternal nurturanceavailability and personality adjustment among college males. Journal of Consulting and Clinical Psychology, 40, 339-342.

Rödholm, M., \& Larsson, K. (1982). The behavior of human male adults at their first contact with a newborn. Infant Behavior and Development, 5, 121-130.

Russell, G. (1982. Primary caretaking and role-sharing fathers. In M. E. Lamb (Ed.), Nontraditional families (pp. 139-172). Hillsdale, NJ: Erlbaum.

Sagi, A. (1982). Antecedents and consequences of various degrees of paternal involvement in child rearing: The Israeli project. In M. E. Lamb (Eds.), Nontraditional families: Parenting and child development (pp. 205-228). Hillsdale, NJ: Erlbaum.Shears, J., Robinson, J., \& Emde R. (2002). Fathering relationships and their associations with juvenile delinquency. Infant Mental Health Journal. Volume 23 issue 1-2, 79-87.

Shears, J., Robinson, J., \& Emde R. (2002). Fathering relationships and their associations with juvenile delinquency. Infant Mental Health Journal. Volume 23 issue 1-2, 79-87.

Shears, J. \& Robinson, J. (2005) Fathering attitudes and practices: Influences on children's development. Child Care in Practice, Volume 11, (1).

Snarey, J. (1993). How fathers care for the next generation: A four-decade study. MA: Harvard University Press.

Strauss, A., \& Corbin, J. (1998). Basics of qualitative research: Grounded theory procedures and techniques (2nd ed.). Newbury Park, CA: Sage.

Storey, A. E., Walsh, C. J., Quinton, R. L., \& Wynne-Edwards, R. E. (2000). Hormonal correlates of paternal responsiveness in new and expectant fathers. Evolution and Human Behavior, 21, 79-95.

Tanfer K., \& Mott, F. (1997). Data and measurement issues: The meaning of fatherhood for men. Battelle Memorial Institute, prepared for NICHD workshop Improving Data on Male Fertility, Family Formation and Fatherhood, Urban Institute (January, 1997), Washington, DC.

Thornberry, T., Freeman-Gallant, A., Lizotte, A., Krohn, M., \& Smith, C. (2003). Linked lives: The intergenerational transmission of antisocial behavior. Journal of Abnormal Child Psychology, 31, 171-184.

Toth, J., \& Xu, X. (1999). Ethnic and cultural diversity in fathers' involvement: A racial/ethnic comparison of African American, Hispanic, \& White fathers. Youth and Society, 31, 76-99.

Wilkie, J. R. (1993). Changes in U.S. men's attitudes toward the family provider role, 1972-1989. Gender and Society, 7, 261-279.

Yogman, M. W. (1981). Games fathers and mothers play with their infants. Infant Mental Health Journal, 2, 241-248.

Jeffrey Shears, $\mathrm{PhD}$, is assistant professor, School of Social Work, Colorado State University. Jean Ann Summers, PhD, is research associate professor, University of Kansas, Beach Center on Disability. Kimberly Boller, PhD, is Senior Research Psychologist, Mathematica Policy Research. Gina BarclayMcLaughlin, PhD, is associate professor, University of Tennessee, Knoxville. Correspondence regarding this article may be addressed to the first author at jeffrey.shears@colostate.edu or Colorado State University, 131 Education Bldg, Fort Collins, Colorado 80523.

Authors' note. Research reported in this article was supported by grants from the National Institute of Child Health and Human Development and the Administration on Children, Youth and Families as part of the Early Head Start Research and Evaluation (EHSRE) and Fathers Involvement with Toddlers Study.

Manuscript received: March 19, 2004

Revised: July 13, 2004

Accepted: August 19, 2004 